\title{
Modelo computacional interactivo, semi-automatizado y de código abierto aplicado a la vigilancia de virus respiratorios
}

\author{
Interactive, semi-automatized and open source computational model applied to respiratory \\ viruses surveillance
}

\author{
Felipe Reyes ${ }^{1}$, Marcela Ferrés ${ }^{1,2}$, Pablo Vial ${ }^{3}$, Valeska Vollrath ${ }^{4}$, Rossanna Camponovo5, \\ Luisa Montecinos ${ }^{6}$, Tamara Hirsch ${ }^{7}$, Patricia Valenzuela ${ }^{7}$ C Cecilia Perret ${ }^{1}$
}

\author{
1'Departamento de Enfermedades Infecciosas e Inmunología Pediátricas. Escuela de Medicina. Pontificia Universidad Católica de Chile. \\ ${ }^{2}$ Laboratorio de Infectología y Virología Molecular Red de Salud UC CHRISTUS. \\ ${ }^{3}$ Instituto de Ciencias e Innovación en Medicina (ICIM). Facultad de Medicina Clínica Alemana, Universidad del Desarrollo. \\ ${ }^{4}$ Laboratorio Clínico. Clínica Alemana. \\ ${ }^{5}$ Laboratorio Integramédica - BUPA. \\ ${ }^{6}$ Laboratorio de Microbiología y Medicina Molecular. Hospital de Enfermedades Infecciosas Dr. Lucio Córdova. \\ ${ }^{7}$ Departamento de Pediatría. Escuela de Medicina. Pontificia Universidad Católica de Chile.
}

Financiado por: Departamento de Enfermedades Infecciosas e Inmunología Pediátricas. Escuela de Medicina. Pontificia Universidad Católica de Chile. No existen conflictos de interés que declarar.

Recibido: 10 de septiembre de 2019 / Aceptado: 7 de enero de 2020

\section{Resumen}

Las infecciones respiratorias agudas (IRA) causadas por virus son una importante causa de morbilidad y mortalidad en el mundo, afectando principalmente a niños y adultos mayores. Se asocian a un alto número de consultas y hospitalizaciones, a una significativa sobrecarga del sistema de salud y a un alto costo económico. La vigilancia de virus respiratorios tiene el potencial de ayudar a optimizar la respuesta sanitaria, garantizar la disponibilidad de recursos humanos, racionalizar los recursos y disminuir los costos asociados a la atención en salud. Con el objetivo de optimizar la recolección $\mathrm{y}$ visualización de los datos de nuestro actual sistema de vigilancia de virus respiratorios, se diseñó una plataforma basada en $\mathrm{R}$ y sus paquetes Shiny, que permite la creación de una interfase web interactiva y amigable para la recolección, análisis y publicación de los datos. Se ingresaron a esta plataforma los datos de la red de vigilancia metropolitana de virus respiratorios disponibles desde 2006. En esta plataforma, el investigador demora menos de un minuto en registrar los datos. El análisis y publicación es inmediato, llegando a cualquier usuario con un dispositivo conectado a Internet, quien puede elegir las variables a consultar. Con un costo muy bajo, en poco tiempo y utilizando el lenguaje de programación $\mathrm{R}$, se logró crear un sistema simple e interactivo, disminuyendo el tiempo de carga y análisis de datos de forma considerable, posiblemente aumentando el impacto y la disponibilidad de esta vigilancia.

Palabras clave: Vigilancia; virus respiratorios; infección respiratoria aguda; R; Internet.

\begin{abstract}
Acute respiratory infections (ARI) are an important cause of morbidity and mortality worldwide, affecting mainly children and the elderly. They are associated with a high economic burden, increased number of medical visits and hospitalizations. The surveillance of the circulation of respiratory viruses can reduce the health care associated costs, and to optimize the health response. A platform based on $\mathrm{R}$ and its package Shiny was designed, to create an interactive and friendly web interface for gathering, analysis and publication of the data. The data from the Chilean metropolitan respiratory viruses surveillance network, available since 2006, was uploaded into the platform. Using this platform, the researcher spends less than 1 minute to upload the data, and the analysis and publication is immediate, available to be seen by any user with a device connected to Internet, who can choose the variables to be displayed. With a very low cost, in a short time, and using the $\mathrm{R}$ programming language, it was possible to create a simple, and interactive platform, considerably decreasing the upload and analysis time, and increasing the impact and availability of this surveillance.
\end{abstract}

Keyword: Surveillance; respiratory viruses; acute respiratory infections; R; Internet. 


\section{Introducción}

Las infecciones respiratorias agudas (IRA) virales son una importante causa de morbilidad y mortalidad en el mundo. Afectan principalmente a niños y adultos mayores, con la mayor carga de enfermedad en países de bajos recursos ${ }^{1,2}$, siendo uno de los motivos de consulta más frecuente, con una alta carga económica por ausentismo escolar, laboral, y gasto en tratamientos ${ }^{3-5}$. Se ha descrito una correlación temporal entre la circulación de virus respiratorios y el aumento en el uso de antimicrobianos ${ }^{6}$. Por este motivo, la identificación de los agentes etiológicos virales podría disminuir el uso de antimicrobianos, especialmente en la población pediátrica. Una adecuada vigilancia epidemiológica y su difusión universal, favorece la anticipación en la disponibilidad y uso adecuado de recursos ${ }^{7}$. En Chile, entre 32 y $58 \%$ de las consultas en atención primaria son por IRA, constituyendo $89 \%$ de las hospitalizaciones en la Región Metropolitana ${ }^{8}$, un claro patrón estacional. Se ha descrito que entre 1 y $3 \%$ de la población bajo 12 meses de edad, se hospitaliza anualmente por bronquiolitis, cuya principal etiología son agentes virales como virus respiratorio sincicial (VRS), metapneumovirus (MPV) y rinovirus9. La vigilancia de virus respiratorios y la difusión de ésta, tiene el potencial de disminuir los costos asociados a la atención en salud, disminuyendo el uso innecesario de tratamientos al permitir al médico clínico el conocimiento, en tiempo real, del comportamiento epidemiológico de los distintos virus respiratorios, y ayuda a optimizar la respuesta sanitaria, en especial en la gestión de camas críticas. En Chile, los datos de la vigilancia de virus respiratorios son utilizados por múltiples organizaciones y médicos clínicos para orientar su respuesta estacional a los virus respiratorios.

Nuestra institución, en conjunto con otros centros de salud, realiza desde 1998 una vigilancia de síndromes respiratorios como enfermedad tipo influenza, laringitis aguda, bronquitis obstructiva y fiebre faringo-conjuntival, en la que participan el Servicio de Urgencias y la consulta de morbilidad pediátrica del Centro Médico San Joaquín de la Red de Salud UC-Christus y el Consultorio N ${ }^{\circ}$, Servicio Metropolitano Central, Santiago. Adicionalmente se realiza vigilancia de los virus respiratorios circulantes (influenza, VRS, parainfluenza, adenovirus (ADV), MPV, rinovirus, enterovirus, coronavirus, bocavirus) en adultos y niños de distintas áreas geográficas de Santiago, Osorno y Puerto Montt, con la participación de la Red de Salud UC- Christus, Clínica Alemana de Santiago y Universidad del Desarrollo (UDD), Integramédica, Hospital Lucio Córdova, Hospital de Puerto Montt Dr. Eduardo Schütz Schroeder y Hospital Base San José de Osorno ${ }^{10}$. Esta vigilancia, es una estimación de la magnitud de la circulación y temporalidad de los virus respiratorios, pero no permite calcular incidencia al desconocer el denominador. Esto se debe a que la notificación de casos depende del número de personas que consulta, de la solicitud de exámenes por los tratantes y de la disponibilidad exámenes para diagnóstico virológico y no representa a la totalidad de individuos que presentan una infección respiratoria. Por esta razón, no se puede comparar en forma fidedigna la magnitud de los brotes. En la actualidad, los datos son entregados de forma agregada por cada centro, analizados e ingresados manualmente a planillas de Microsoft Excel $^{\circledR}$, graficados con el mismo software y enviados para publicar en el sitio web (http://virus.uc.cl) por un departamento externo. Luego se envía a distintas autoridades sanitarias como el Ministerio de Salud y el Instituto de Salud Pública, y se difunde internamente a las instituciones participantes, que a su vez distribuyen los resultados a su personal de salud. Esto requiere de al menos dos horas de trabajo semanal, y tiene la limitación de estar sujeto al error de digitación manual, pérdida de datos para análisis al agruparlos, y tiempos de demora en su publicación.

Recientemente, el desarrollo del lenguaje de programación $\mathrm{R}^{11}$, $\mathrm{y}$ en particular el paquete Shiny para $\mathrm{R}^{12}$, ha permitido mostrar de forma interactiva la salida de los análisis realizados en $\mathrm{R}$ en los navegadores web, sin necesidad de manejar otro lenguaje de programación. Dada la naturaleza general del lenguaje $R$, es posible programar análisis interactivos con una interfase de navegador web Shiny que puede verse en cualquier dispositivo conectado a Internet.

Por esto, nos propusimos diseñar e implementar un sistema semi-automatizado e interactivo para la recolección, análisis y publicación de los datos de la vigilancia de virus respiratorios, que permita simplificar el trabajo de recolección y publicación de resultados y mejorar la visualización e interacción por los usuarios finales.

\section{Materiales y Métodos}

Se diseñó una plataforma basada en R y Shiny para la creación de una interfase web interactiva y fácil de usar. Se utilizó el paquete de R ggplot para la realización de los gráficos ${ }^{13}$. Lo anterior fue montado sobre un servidor Linux con el sistema operativo Ubutnu 16.04. Para la entrada, procesamiento y análisis de los datos, se ocuparon además los paquetes de $\mathrm{R}$ detallados en la Tabla 1 . Se diseñó una base de datos con variables demográficas como edad, y virus identificados (Tabla 2), además de un comentario semanal realizado por un investigador. Para la publicación de los datos, se definieron dos categorías: "virus tradicionales" (influenza, VRS, parainfluenza, ADV y MPV), y "virus no tradicionales" (rinovirus/enterovirus, coronavirus, bocavirus), y tres grupos etarios: lactantes bajo 1 año de edad, pacientes entre 1 y 14 años, y pacientes 


\begin{tabular}{|ll|}
\hline $\begin{array}{l}\text { Tabla 1. Listado de software y paquetes utilizados en la } \\
\text { plataforma }\end{array}$ \\
\hline Software / Paquete de $\mathbf{R}$ & Versión \\
\hline R & 3.5 .3 \\
\hline R Studio & 1.1 .463 \\
\hline Shiny & 1.2 .0 \\
\hline ggplot2 & 3.1 .0 \\
Dplyr & 0.7 .8 \\
Lubridate & 1.7 .4 \\
Scales & 1.0 .0 \\
reshape2 & 1.4 .3 \\
\hline Plyr & 1.8 .4 \\
Epitools & $0.5-10$ \\
RPostgreSQL & $0.6-2$ \\
\hline DBI & 1.0 .0 \\
\hline
\end{tabular}

Tabla 2. Variables disponibles de la base de datos

\begin{tabular}{|c|c|}
\hline Variable & Detalle de la variable \\
\hline \multicolumn{2}{|c|}{ Tabla de Comentarios } \\
\hline Com & Comentario de la semana \\
\hline com se & Semana epidemiológica del comentario \\
\hline com_año & Año del comentario \\
\hline \multicolumn{2}{|l|}{ Tabla de Virus } \\
\hline ID & Correlativo del caso \\
\hline f_nac & Fecha de nacimiento del paciente \\
\hline f_examen & Fecha de toma del examen \\
\hline Virus & Virus detectado en el examen \\
\hline Centro & Centro donde se tomó o analizó la muestra \\
\hline
\end{tabular}

$\geq 15$ años, todas categorías usadas en la vigilancia actual. Cada centro recolectó sus datos de forma independiente desde sus propios sistemas informáticos y los transfirió las variables solicitadas a una planilla. A través de la plataforma web diseñada, el investigador, quien accede con un nombre de usuario y contraseña individual, sube semanalmente las planillas enviadas desde los centros participantes, quedando los datos guardados de forma automatizada en la base de datos. Para garantizar la privacidad y la seguridad del sistema, los datos se envían de forma encriptada bajo los protocolos de Transport Layer Security (TSL) y Hypertext Transfer Protocol Secure (HTTPS $)^{14}$ a una base de datos PosgreSQL, a la que es posible acceder desde fuera del servidor solo mediante túnel Secure Shell $(\mathrm{SSH})^{15}$ y una llave RSA de 2048 bit $^{16}$. Los datos se mantienen anonimizados durante todo el proceso. El usuario final sólo puede acceder a los gráficos de datos agrupados.

Una vez digitados y registrados los datos, éstos quedan inmediatamente disponibles para la aplicación, la que grafica de forma automática e interactiva la circulación de los virus respiratorios en el tiempo. Inmediatamente desde que el investigador sube los datos, el usuario final tiene disponibles distintas pestañas para visualizar e interactuar según lo que quisiera ver y analizar. En la Figura 1 se puede observar un esquema simplificado del sistema.

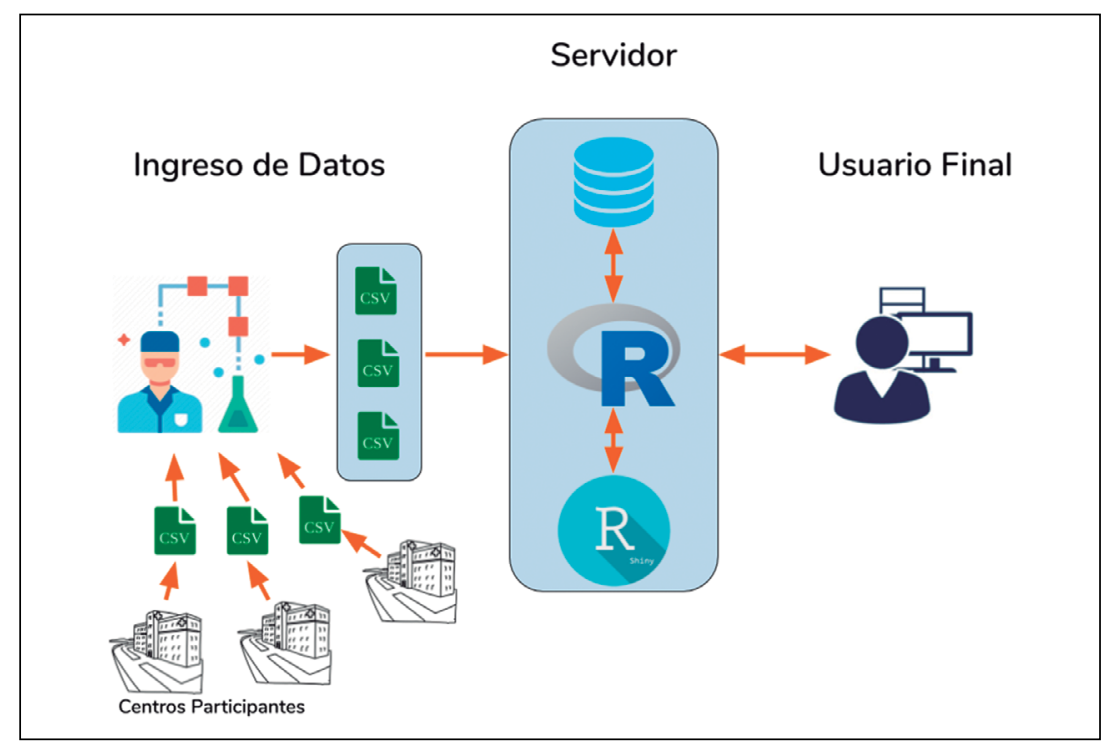

Figura 1.1. Esquema de funcionamiento del sistema de vigilancia integrado. Cada centro participante envía semanalmente los datos a los investigadores, quienes ingresan los datos en una planilla CSV, los que son subidos al sistema a través de una interfase creada por Shiny, procesados por R y almacenados en la base de datos. En el servidor R, lee la base de datos y procesa variables requeridas por Shiny. Estas variables son elegidas por el usuario final, quien ve en el navegador el resultado en forma de gráficos e informes según las variables ingresadas.

\section{Servidor}

\section{Procesamiento de datos Usuario Final}

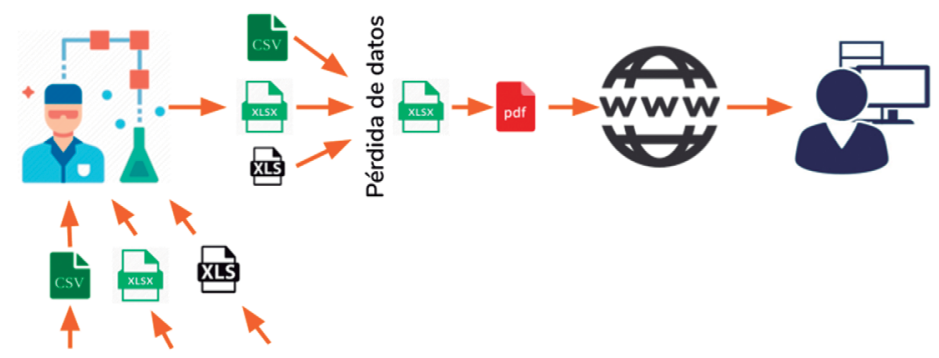

Pérdida de datos

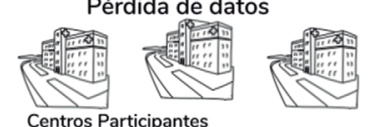

Figura 1.2. Esquema de funcionamiento del antiguo sistema de vigilancia. Cada centro participante enviaba semanalmente los datos agregados al investigador en planillas con formatos diferentes. El investigador generaba una tabla de datos, agregada, perdiendo las variables individuales. Luego las analizaba, graficaba y exportaba como imagen fija o PDF. Este documento era luego subido por un tercero a una página web estática, donde el usuario final no podía interactuar. 
Los datos son respaldados semanalmente en triplicado por el proveedor del servidor, bajo un sistema de almacenamiento "en la nube" y en un servidor instalado físicamente en nuestras dependencias. Para poner en marcha el sistema se homologaron los datos recolectados previamente entre los años 2006 y 2018, éstos fueron ingresados a la base de datos, siendo posible su visualización actualmente.

\section{Resultados}

La recolección de datos mediante el nuevo sistema logró sistematizar 3.928 semanas epidemiológicas entre los años 2006 y 2019, considerando los cinco virus tradicionales. Esto corresponde a $100 \%$ de los datos previamente disponibles. Además, se incluyeron 480 comentarios semanales disponibles, los que fueron adaptados y subidos a la base de datos. En el sistema antiguo los datos se guardaban agrupados por grupos etarios $(<1$ año, 1-14 años y $>14$ años) y semanas, perdiendo precisión en el análisis. Ahora se encuentran almacenados en forma individualizada, caso a caso, por fecha y con edad exacta en días, permitiendo, si se requiere a futuro, analizar en forma más precisa, las variaciones en la circulación de los

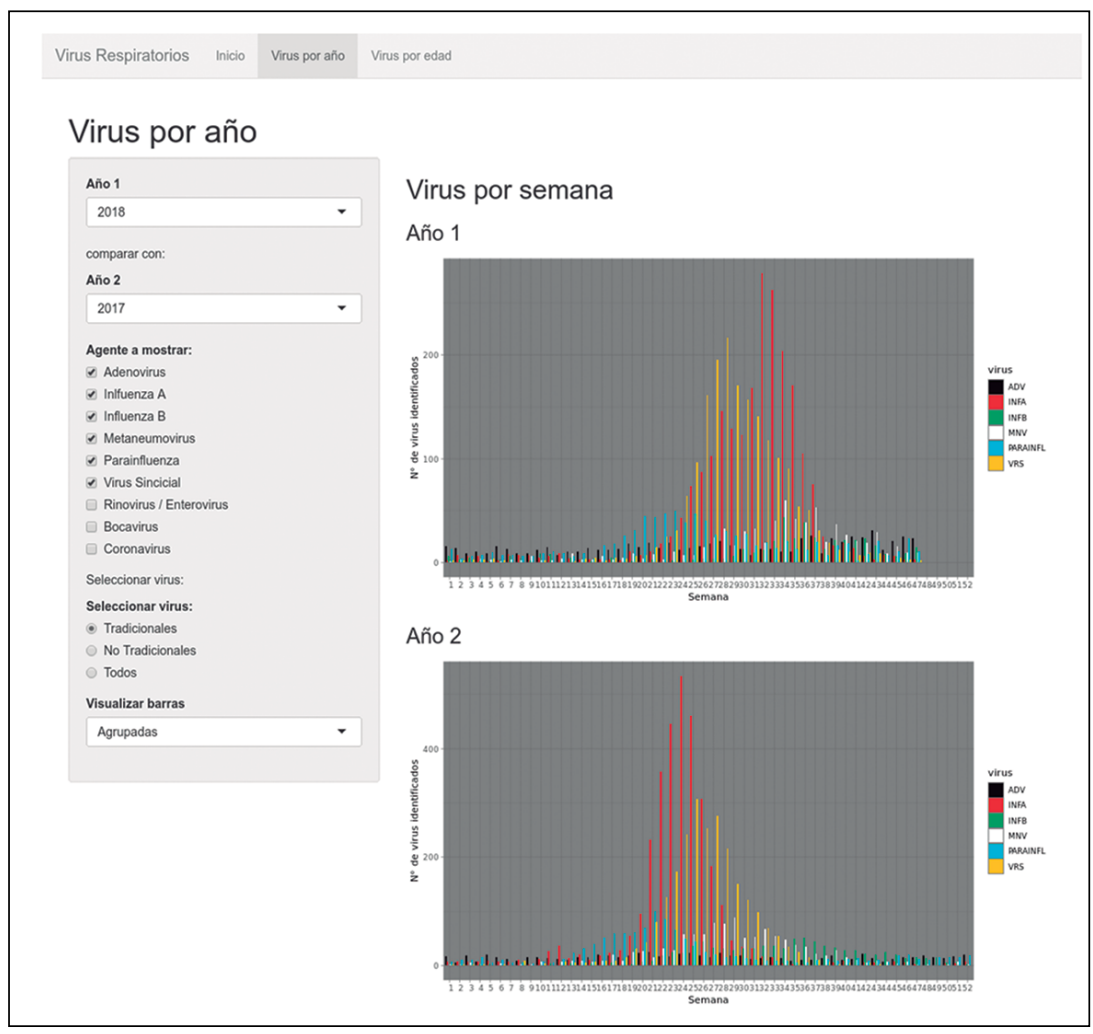

Figura 2. Ejemplo de interfaz del usuario final y gráficos de circulación de virus por semana epidemiológica. Se muestra la comparación de los virus respiratorios tradicionales entre dos años. virus en los distintos grupos etarios. De todas maneras, también con este método, el usuario final visualiza los resultados en las tres categorías de edad especificadas. Actualmente, cada centro fuente no necesita agrupar sus datos por grupo etario, disminuyendo el tiempo utilizado con el sistema antiguo, aunque el tiempo adicional requerido para este trabajo no fue medido.

Se midió el tiempo que demora en subir los datos por parte del investigador a la plataforma automatizada, siendo inferior a 1 minuto. En el sistema antiguo, la alimentación de la base de datos, basada en las planillas desde los centros, que venían en distintos formatos, tomaba al menos dos horas. Con respecto al proceso de análisis de los datos en esta nueva plataforma, una vez subidos los datos, quedan disponibles de forma inmediata en el sistema para ser visualizados.

Utilizando la plataforma actualizada, el usuario final dispone de tres pestañas donde puede ver el comentario de la semana, la distribución anual de los virus respiratorios y la distribución etaria anual o por semana epidemiológica de los virus tradicionales y no tradicionales desde el año 2006 a la fecha. En el comentario de la semana, se visualizan el análisis de la circulación de los virus respiratorios por semana epidemiológica y por grupo etario y el comportamiento de las consultas de los cuatro síndromes respiratorios reportados por los centros centinelas. A diferencia del modelo antiguo (Figura 4), el usuario puede actualmente seleccionar la o las semanas epidemiológicas para ver los comentarios. La plataforma también permite hacer comparaciones entre años y la circulación de virus respiratorios (Figura 2) y entre virus respiratorios por grupos etarios y distintos años o semanas epidemiológicas (Figura 3), algo que no era posible en el sistema de vigilancia antiguo (Figura 4).

Es novedoso en este sistema que el tamaño y distribución de la interfase gráfica se adapta automáticamente al tamaño de la pantalla del dispositivo utilizado por el usuario, por lo que puede ser utilizada por cualquier dispositivo que cuente con un navegador web como celulares, tabletas y computadores.

Por último, cabe destacar que el software no tiene costo, ya que todos los programas utilizados son de código abierto y el código utilizado fue diseñado por el investigador principal. Este código del software se encuentra disponible bajo licencia GNU GPL $3^{17}$ en https:// gitlab.com/morksoldat/vigilancia-virus-respiratorios. Esto permite su utilización en forma libre para generar un sistema similar.

El costo del servidor, que se encuentra arrendado a una empresa externa, es de aproximadamente $\$ 95.000$ pesos chilenos (USD \$140) anuales. El tiempo empleado en la creación y puesta en marcha de todo el sistema fue de un año considerando que el tiempo dedicado era compartido con otras actividades. 
Se encuentra disponible un modelo de pruebas, el cual puede ser utilizado de forma gratuita desde el sitio https:// virusresp.xyz/virus/.

\section{Discusión}

El desarrollo e implementación de nuevas tecnologías en informática médica permite disminuir el error de escritura, sistematizar la información disponible, reducir costos y tiempos, y masificar la información de forma instantánea a todo aquel que posea una conexión a Internet ${ }^{18}$. Sin embargo, no se ha demostrado que esto tenga un impacto en la actividad clínica ${ }^{19}$. En nuestra experiencia, la plataforma desarrollada permite ahorrar tiempo a los investigadores, posiblemente disminuir el error de transcripción, y mostrar los resultados de forma inmediata. Al ser interactivo y automatizado, permite obtener una visión más oportuna y personalizada del comportamiento de los virus respiratorios permitiendo además la comparación entre distintos años de circulación, según las preferencias del usuario.

En la nueva plataforma se almacenan los datos de cada caso, y no una tabla de datos agrupados como era previamente. Esto permitirá a los investigadores en un futuro la utilización de los casos individuales (anónimos), para análisis con mayor detalle y con otras finalidades. A modo de ejemplo, con el sistema actual, al quedar registrados el subtipo de virus detectado (ej. VRS A o B), la fecha de

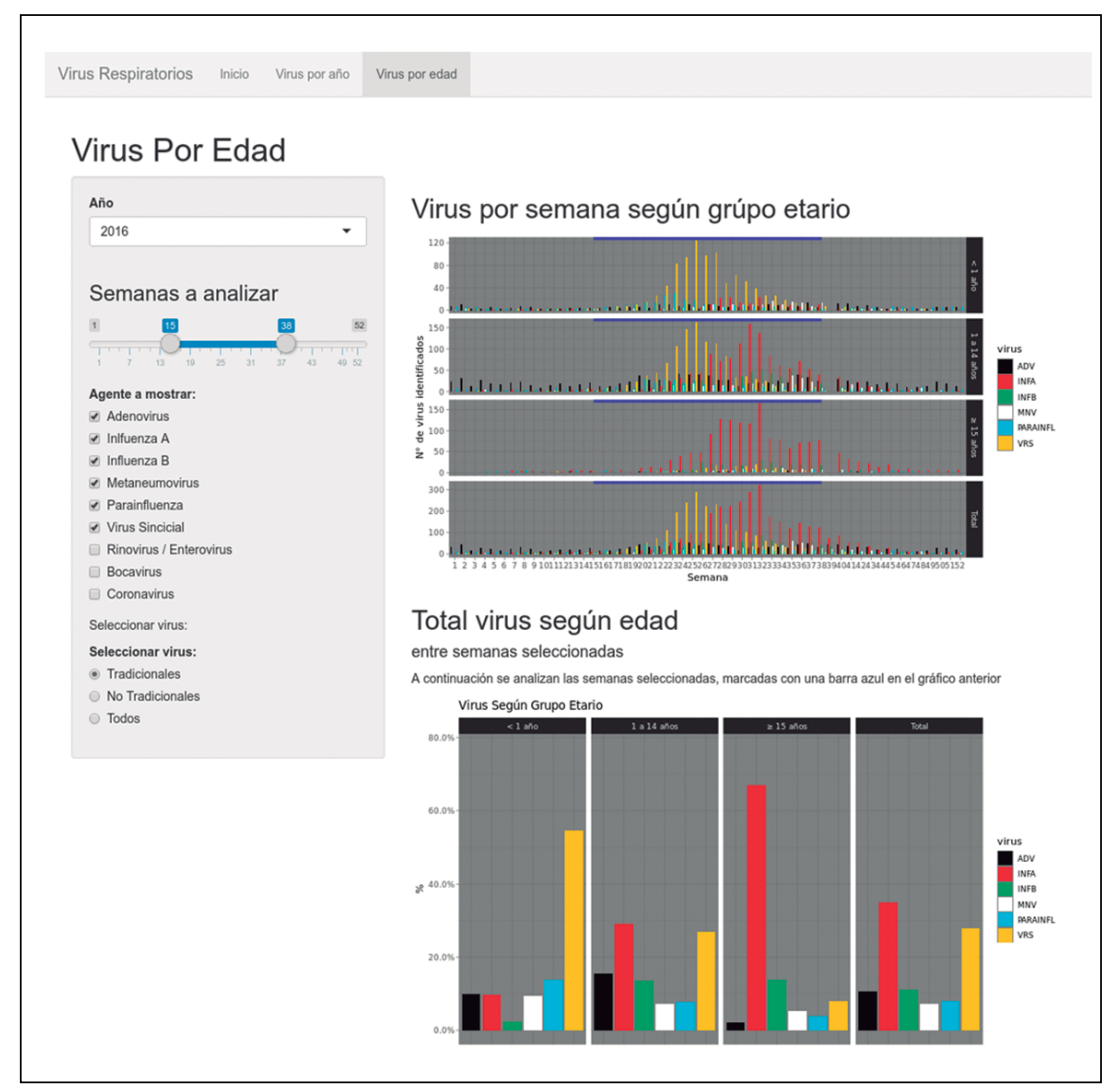

Figura 3. Ejemplo de interfaz del usuario final y gráficos de circulación de virus tradicionales por semana epidemiológica y la proporción de cada virus por grupo etario en 1 año.

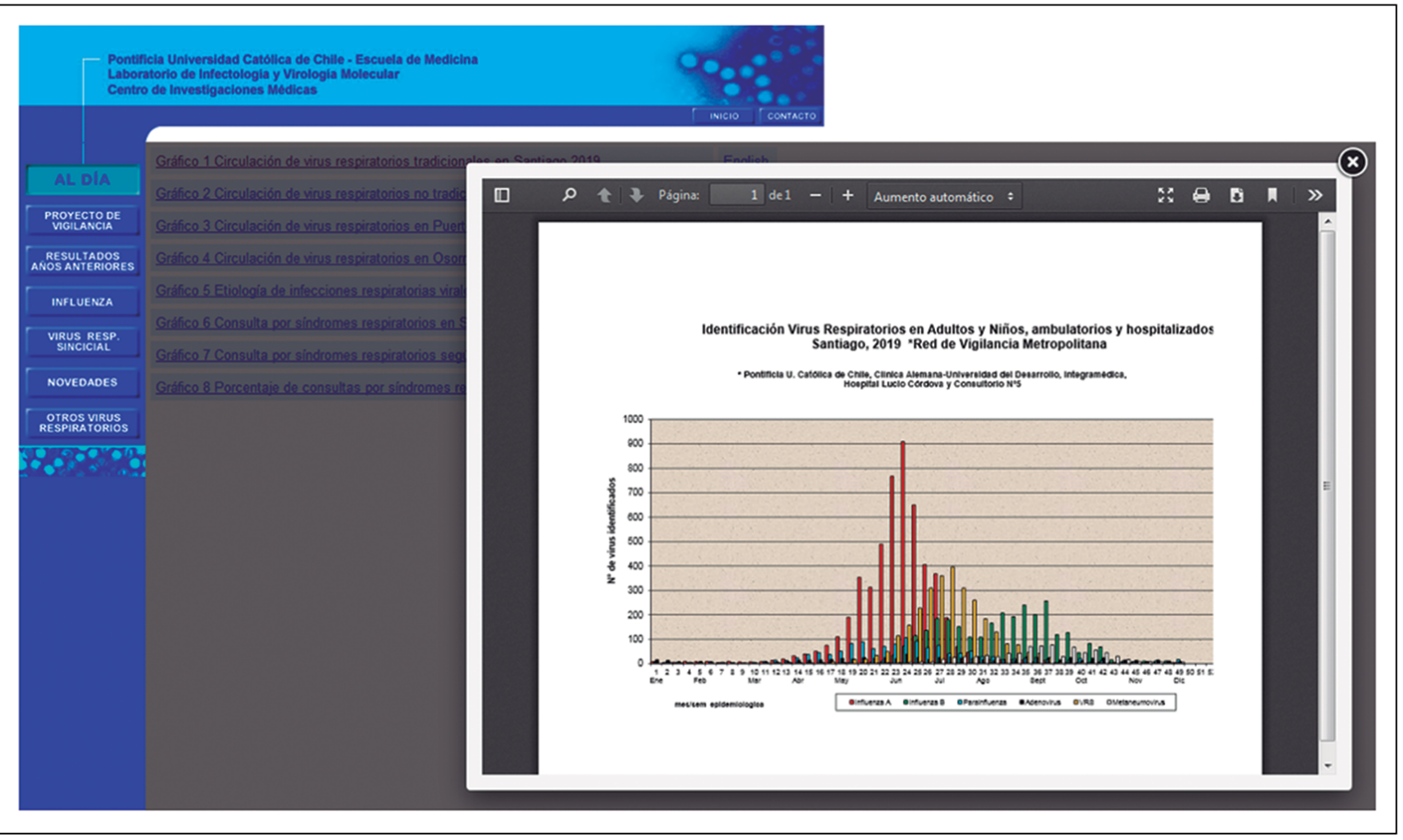

Figura 4. Sitio Web Antiguo. 
nacimiento de cada caso, y la fecha exacta de la ocurrencia del caso, permitiría correlacionar estas variables de mejor forma entre sí, o con otras variables, como las mediciones diarias de contaminantes ambientales.

El lenguaje de programación $\mathrm{R}$ requiere entrenamiento, pero dentro del ámbito de investigación en medicina es ampliamente utilizado ${ }^{20}$. Shiny permite poner a disposición de cualquier persona sin entrenamiento, los resultados desarrollados con este lenguaje $\mathrm{e}^{12}$. La utilización de software de código abierto permite que esta herramienta quede disponible para que cualquiera lo pueda reutilizar de forma libre, siempre y cuando respete la licencia en la que está publicado. En este caso particular, cualquiera es libre de ver, estudiar y copiar el código aquí presentado, siempre y cuando el resultado se publique bajo las mismas condiciones declaradas en la licencia ${ }^{17}$. Utilizar estas dos herramientas en conjunto permite generar una aplicación interactiva de manera rápida y fácil. Con tiempo dedicado en forma exclusiva, se estima que el desarrollo de un sistema similar por alguien con experiencia no debiera tardar más que algunas semanas.

Dado que la plataforma actual es más fácil de visualizar que la anterior, compatible con nuevos dispositivos como teléfonos celulares y tabletas, y disponible de forma inmediata desde que se cargan los datos, las autoridades sanitarias, médicos clínicos e investigadores pueden acceder fácilmente a los datos, realizar análisis y comparaciones, facilitando la interpretación y la accesibilidad de la información. Es posible también que, al haber simplificado la recolección de datos, se pueden agregar más centros participantes y zonas geográficas, sin requerir de mayor personal o tiempo del mismo, haciendo la vigilancia fácil y rápidamente ampliable.

La mayor disponibilidad y fácil difusión de los datos, entre otras cosas, podría permitir al médico clínico sospechar el diagnóstico de virus respiratorios en sus pacientes, especialmente adultos y adultos mayores, donde el diagnóstico de virus suele ser infrecuente, reduciendo así el uso inapropiado de antimicrobianos y facilitando el diagnóstico de infecciones virales susceptibles de ser tratadas en forma específica ${ }^{21}$. Del mismo modo, se permite una adecuada toma de decisiones en términos de medidas preventivas oportunas ${ }^{22}$. Este modelo de vigilancia y el uso de esta plataforma puede ser adaptado, con pocas modificaciones, para otras vigilancias en el ámbito sanitario como resistencia bacteriana, IAAS, al obtener los datos directamente de las bases de datos disponibles en cada centro o servicio clínico, facilitando la difusión y análisis en tiempo real, con la posibilidad de detectar variaciones en forma oportuna y con ello tomar medidas en forma rápida e informada. Existen algunos ejemplos de aplicaciones similares en la página web del desarrollador de Shiny ${ }^{23}$ y en la literatura médica ${ }^{24}$. La implementación de herramientas de visualización de datos orientadas hacia la epidemiología de enfermedades infecciosas es compleja, presenta múltiples barreras para su creación y adopción, y su impacto no está claro ${ }^{25}$. Nuestra plataforma sigue las recomendaciones de construir herramientas interoperables, colaborativas e inter-institucionales, de libre acceso y bajos requerimientos en recursos ${ }^{25}$. Además, realizaremos un seguimiento de la misma con lo que esperamos poder medir de mejor forma su impacto y realizar mejoras.

\section{Conclusión}

La utilización de software de código abierto permite la creación de sistemas de vigilancia interactivas de forma económica, rápida, ahorrando tiempo a los investigadores, entregando los resultados de forma inmediata, interactiva y accesible a toda la comunidad. La disponibilidad de la información en forma rápida e interactiva podría permitir un mejor análisis y tomar medidas oportunas por los usuarios destinatarios del sistema. Este modelo de vigilancia puede ser aplicado a otras vigilancias, de interés en infectología como resistencia a antimicrobianos e IAAS

\section{Referencias bibliográficas}

1.- Liu L, Johnson H L, Cousens S, Perin J, Scott S, Lawn J E, et al. Global, regional, and national causes of child mortality: an updated systematic analysis for 2010 with time trends since 2000. The Lancet 2012; 379: 2151-61. https://doi.org/10.1016/S0140-6736(12)605601

2.- Walker C L F, Rudan I, Liu L, Nair H, Theodoratou E, Bhutta Z A, et al. Global burden of childhood pneumonia and diarrhoea. The Lancet 2013; 381: 1405-16. https://doi. org/10.1016/S0140-6736(13)60222-6.
3.- Adams P F, Hendershot G E, Marano M A Centers for Disease Control and Prevention/ National Center for Health Statistics. Current estimates from the National Health Interview Survey, 1996. Vital Health Stat 10 1999; 200: 1-203. PMID: 15782448 .

4.- Fendrick A M, Monto A S, Nightengale B, Sarnes M. The economic burden of noninfluenza-related viral respiratory tract infection in the United States. Arch Intern Med 2003; 163: 487. https://doi.org/10.1001/ archinte.163.4.487.

5.- Troeger C, Blacker B, Khalil I A, Rao PC, Cao $\mathrm{J}$, Zimsen S R M, et al. Estimates of the global, regional, and national morbidity, mortality, and aetiologies of lower respiratory infections in 195 countries, 1990-2016: a systematic analysis for the Global Burden of Disease Study 2016. Lancet Infect Dis 2018; 18: 1191-210. https:// doi.org/10.1016/S1473-3099(18)30310-4.

6.- Ryu S, Kim S, Kim B I, Klein E Y, Yoon Y K, Chun B C. Temporal relationship between antibiotic use and respiratory virus activities in the Republic of Korea: a time-series analysis. Antimicrob Resist Infect Control 2018; 7: 56. https://doi.org/10.1186/s13756-018-0347-8.

7.- Choi S, Kabir R, Gautam-Goyal P, Malhotra P. Impact of respiratory viral panel 
polymerase chain reaction assay turnaround time on length of stay and antibiotic use in patients with respiratory viral illnesses. Hosp Pharm 2017; 52: 640-4. https://doi. org/10.1177/0018578717731573.

8.- Ministerio de Salud. Guía Clínica Infección Respiratoria Aguda Baja de Manejo Ambulatorio en Menores de 5 Años. 2013. https://www.minsal.cl/portal/url/item/7220fdc4 341244a9e04001011f0113b9.pdf.

9.- Zhou H, Thompson W W, Viboud C G, Ringholz C M, Cheng P-Y, Steiner C, et al. Hospitalizations associated with influenza and respiratory syncytial virus in the United States, 1993-2008. Clin Infect Dis 2012; 54: 1427-36. https://doi.org/10.1093/cid/cis211.

10.- Pontificia Universidad Católica de Chile. Proyecto de Vigilancia de Virus Respiratorios n.d. http://virus.uc.cl/virus_respiratorios/ bienvenida.html (accessed April 11, 2019).

11.- R Core Team. R: A language and environment for statistical computing. Vienna, Austria: R Foundation for Statistical Computing; 2019.

12.- Chang W, Cheng J, Allaire J J, Xie Y, McPherson J. shiny: Web Application Framework for R. 2018.

13.- Wickham H. Ggplot2: elegant graphics for data analysis. New York: Springer; 2009.

14.- Rescorla E, Schiffman A. The Secure HyperText Transfer Protocol. RFC Editor; 1999. https://doi.org/10.17487/rfc2660.

15.- Ylonen T. SSH - Secure login connections over the Internet. Proc. 6th USENIX Secur. Symp., United States: USENIX Association; 1996, p. 37-42.

16.- Rivest R L, Shamir A, Adleman L. A method for obtaining digital signatures and public-key cryptosystems. Commun ACM 1978; 21: 120 6. https://doi.org/10.1145/359340.359342.

17.- GNU General Public License. Free Software Foundation; 2007.

18.- Hersh W R. Medical Informatics: improving health care through Information. JAMA 2002; 288: 1955. https://doi.org/10.1001/ jama.288.16.1955.

19.- Black A D, Car J, Pagliari C, Anandan C, Cresswell K, Bokun T, et al. The impact of ehealth on the quality and safety of health care: a systematic overview. PLoS Med 2011; 8: e1000387. https://doi.org/10.1371/journal. pmed.1000387.

20.- Muenchen R A. The popularity of data science software. R4statsCom 2019. http://r4stats. com/articles/popularity/ (accessed February 1,
2020).

21.- Semret M, Schiller I, Jardin B A, Frenette C, Loo V G, Papenburg J, et al. Multiplex respiratory virus testing for antimicrobial stewardship: a prospective assessment of antimicrobial use and clinical outcomes among hospitalized adults. J Infect Dis 2017; 216: 93644. https://doi.org/10.1093/infdis/jix288.

22.- Armour P A, Nguyen L M, Lutman M L, Middaugh J P. Evaluation of the Novel Respiratory Virus Surveillance Program: Pediatric Early Warning Sentinel Surveillance (PEWSS). Public Health Rep 2013; 128: 88-96. https://doi.org/10.1177/00333549131280S213.

23.- Gallery. Shiny. https://shiny.rstudio.com/ gallery/ (accessed January 2, 2020).

24.- Wahi M M, Dukach N. Visualizing infection surveillance data for policymaking using Open Source Dashboarding. Appl Clin Inform 2019; 10: 534-42. https://doi. org/10.1055/s-0039-1693649.

25.- Carroll L N, Au A P, Detwiler L T, Fu T, Painter IS, Abernethy NF. Visualization and analytics tools for infectious disease epidemiology: A systematic review. J Biomed Inform 2014;51: 287-98. https://doi.org/10.1016/j. jbi.2014.04.006. 